\title{
Trends in the Brain-Computer Interface
}

\author{
Matej Kostrec ${ }^{1}$, Bohumír Štědroň2,*
}

1 Information Science and Management Department, Academy of the Police Force in Bratislava, Slovakia

2 Reads lectures at the Charles University and Czech Technical University, Prague, Czech Republic

* Corresponding author: stedron@seznam.cz

\begin{abstract}
The goal of every human being on our planet is to improve the living conditions not only of his life, but also of all humanity. Digitization, dynamic development of technological equipment, unique software solutions and the transfer of human capabilities into the form of data enable the gradual achievement of this goal. The human brain is the source of all activities (physical, mental, decision-making, etc.) that a person performs. Therefore, the main goal of research is its functioning and the possibility to at least partially replace this functioning by external devices connected to a computer. The Brain-Computer Interface $(\mathrm{BCl})$ is a term which represents a tool for performing external activities through sensed signals from the brain. This document describes various techniques that can be used to collect the neural signals. The measurement can be invasive or non-invasive. Electroencephalography (EEG) is the most studied non-invasive method and is therefore described in more detail in the presented paper. Once the signals from the brain are scanned, they need to be analysed in order to interpret them as computer commands. The presented methods of EEG signal analysis have advantages and disadvantages, either temporal or spatial. The use of the inverse EEG problem can be considered as a new trend to solve non-invasive high-resolution $\mathrm{BCl}$.
\end{abstract}

\section{KEYWORDS}

brain-computer interface; electroencephalography (EEG); inverse EEG problem; neuro imaging; medicine, brain activity imaging

DOI

$10.14712 / 23366052.2021 .6$

C 2021 The Authors. This is an open-access article distributed under the terms of the Creative Commons Attribution License (http://creativecommons.org/licenses/by/4.0), which permits unrestricted use, distribution, and reproduction in any medium, provided the original author and source are credited. 


\section{INTRODUCTION}

The concept of human-machine interface, which encompasses all the means and techniques used by man to communicate with a machine, is ubiquitous in today's world. While the computer keyboard and mouse are now used almost daily by part of the population, many studies are still seeking to improve their ergonomics. This improvement can go through the use of new interfaces such as voice, vision or even the positioning of the user in the case of virtual reality. However, we must also be able to respond to cases where all of these interfaces cannot be used. It is therefore interesting to provide other means of communication for users who cannot generate the muscular movements necessary for human-machine interfaces. This is the challenge facing the Brain-Computer Interface (BCI) domain.

$\mathrm{BCI}$, also known as the direct neural interface, is a means of communication that uses brain activity. It is important to note that this is done completely independently of the usual brain peripherals - the peripheral nerves and muscles. The aim of the BCI is therefore to provide the brain with another communication intermediary, under user control, and not to "listen" to its brain activity without its knowledge. There are several areas of application. The first one that comes to mind is necessarily the medical field, where BCI can allow people with disabilities to control a chair, prosthesis or even a hospital bed. But this technology is not necessarily intended for people with disabilities. Indeed, several applications can be envisaged, notably in entertainment, authentication or even neuro-marketing. The BCI world therefore seems to have, from an application point of view, the potential to interest the general public. However, its use is currently far from being widespread in everyone's daily life.

The idea of being able to control a device with the signals generated by brain activity was born in 1929, following Berger's work on the EEG (He, 2013). The notion of BCI appeared in the 1970s with the work of Vidal (1973). This research was carried out under a contract with the Defense Advanced Research Projects Agency (DARPA), which was also involved in the development of early versions of the Internet. These works have shown that it is possible to use signals from brain activity to transmit the will of the user effectively and have initiated decades of research.

The BCI works in the following way. One system acquires and processes brain signals, then another translates and classifies them to transform them into commands. To make it simpler, the subject thinks of what he/she wishes to do, and this information will be transmitted to the computer which will translate it and execute the command (for example: Movement of the person's prosthesis replacing a part of the body which had been amputated to this person.). A real innovation in this digital age.

The one who "dictates" this action is the human brain. Therefore, the brain-machine interface must record brain activity by simply using electrodes installed on the skull, cortex, or even in the brain. Thus, BCI can pick up electrical signals transmitted by neurons. Here's how its two methods of recording electrical signals work. One using invasive acquisition methods and the other one using non-invasive methods.

Invasive $\mathrm{BCI}$ requires neurosurgical surgery. The principle consists in fact by placing electrodes directly on the gray matter to have the least noisy signal possible. This method has the particularity of allowing BCI in the brain sense in the direction from brain to machine but also from machine to brain. Indeed, the electrodes can be used 
to, for example, transmit signals from a camera to the visual cortex, in order to bring artificial vision to blind people. Concerning the direction brain to machine, the use of an invasive acquisition method allows high spatio-temporal resolution to be achieved, allowing faster and more precise response. On the other hand, there are certain problems to be considered. Besides the fact that each application requires a specific placement of electrodes, it is difficult to guarantee the stability of the signal over operating periods at the level of months or years.

Non-invasive methods are mainly distinguished from invasive methods by the fact that they involve much less risk for the user. In fact, they use brain imaging, which does not require surgery. This makes it possible to envisage a single system for measuring brain activity for any application since all of the brain activity can be taken into account. They are also less restrictive for the user. Nevertheless, they suffer from a lack of spatial resolution since the signal is noisy by the passage through the cranium. Several means of measurement can be used, such as Magnetic Resonance Imaging (MRI), Functional Magnetic Resonance Imaging (fMRI), Magnetoencephalography (MEG) or also Electroencephalography (EEG).

The measurement methods like MRI, fMRI and MEG are based on the measurement of magnetic fields, which requires large and expensive equipment. Indeed, MRI machines weigh several tens of tonnes and cost more than 850,000 euros (Sarracanie, LaPierre, Salameh, Waddington, Witzel, \& Rosen, 2015). This is mainly due to the fact that they need a strong magnet in order to generate a stable magnetic field. Any attempt of miniaturization, however, involves decreasing the power of the device's magnet, which decreases the spatial resolution of the measurement. Regarding the MEG, the measuring device required is also relatively large. In addition, since the magnetic fields measured are very weak (of the order of femtoTesla in the case of MEG), magnetic shielding may be necessary around the measuring device in order to avoid the risks of interference with the outside world. These methods based on the measurement of magnetic fields are therefore too cumbersome, and miniaturization is not possible immediately. Therefore, they do not meet the comfort criteria of the $\mathrm{BCI}$ user. These arguments partly explain why EEG is the most studied measurement method for BCI. Indeed, this method, using a helmet on which electrodes are placed, is very simple to wear for the user, in addition to having a very good temporal resolution in comparison with the other non-invasive methods. The latter method therefore seems to be the most suitable for bringing BCI into everyday life, also because the price of EEG helmets varies according to the number of electrodes. This can range from 90 euros for a helmet with a single electrode up to more than 20,000 euros for a helmet with 256 electrodes, which is the highest measurement capacity currently (Farnsworth, 2017).

\section{Interface brain machine by electroencephalography (EEG)}

The principle of the EEG as well as its current use in the framework of the BCI rests on the activity of the brain when it generates electro-chemical exchanges at the level of the neurons. These exchanges create electromagnetic fields which can therefore be considered as images of brain activity. The principle of the BCI is to measure these signals in order to deduce there from a willingness of the patient to transmit to a machine. This field is currently in expansion. 
The potentials measured by EEG are the images of postsynaptic excitatory or inhibitory potentials of neurons. These potentials occur respectively at the entrance of a flow of positive and negative ions in the cell. These neuron-wide events generate a very small potential which does not significantly contribute to the potential measured on the scalp. As a result, the potentials recorded by EEG represent the sum of the potentials generated by thousands or even millions of neurons at the same time. The amplitude of the signals measured on the scalp by EEG, which can reach $300 \mu \mathrm{V}$, is therefore a direct image of the number of synchronous neurons at a given time. An EEG measurement makes it possible to visualize different electromagnetic oscillations, which are called cerebral rhythms. Each rhythm has its own frequency band and corresponds to a specific brain function. The most interesting EEG waves are as follows (Schomer \& Lopes Da Silva, 2012):

- The delta wave, 0.4 to $4 \mathrm{~Hz}$, which characterizes deep sleep.

- The theta wave, 4 at $8 \mathrm{~Hz}$, which characterizes drowsiness.

- The alpha wave, 8 at $13 \mathrm{~Hz}$, which characterizes a calm state of consciousness, contains the MU sub-wave, between 10 and $12 \mathrm{~Hz}$, which dampens the movement of limb contralateral.

- The beta wave, 13 at $30 \mathrm{~Hz}$, which characterizes a period of concentration.

The study of these waves in specific situations can make it possible to deduce possible orders for a BCI.

\section{EEG signal analysis methods}

Potential linked to the event

These are brain responses appearing at fixed time moments after an external event, such as a sensory stimulus, or an internal event, such as thinking of a specific action. There are thus 2 types of potential:

- Exogenous potential is the consequence of an external event. This potential is a physiological response to the stimulus and therefore does not depend on any context.

- Endogenous potential is the consequence of an internal event. This potential can also be context-dependent. For example, if a user tries to locate the letter D in a word, he/she will generate a potential if this letter is presented to him, but nothing is measurable with this same letter if the user searches for the letter $\mathrm{T}$.

The use of these potentials linked to the event is therefore a relatively simple method to set up BCIs. The nature of the potential determines the importance of the training phase when setting up a BCI. If an exogenous potential is used, almost no training is required, the response being physiological. Conversely, if an endogenous potential is implemented, a training phase via a return of the BCI is necessary.

\section{Visually evoked potentials of steady state}

These potentials use a visual stimulus, most often a flashing graphic element. This method is based on the fact when, during the EEG measurements, a peak in amplitude is observed at the same frequency as that of a blinking element in the center of the visual field. The responses are more easily observable for stimulation frequencies between 5 and $27 \mathrm{~Hz}$. It is therefore possible to present different stimuli to the user 
on the same screen. When the user directs his/her gaze on a stimulus, a characteristic EEG signal is then measured and detected to trigger the desired command.

However, this method has its limits. Having to present visual stimuli for each command limits the possibilities for the same screen size. In addition, the need to have to set flashing elements can trigger epileptic seizures and certain stimulation frequencies can cause fatigue as it requires a lot of concentration. This method therefore remains too restrictive and limited in the perspective of a general public BCI.

\section{Desynchronizations and synchronizations linked to the event}

This method is another special case of potentials linked to the event. This corresponds to 2 visible phenomena in the power spectrum of cerebral rhythms which can be triggered by internal or external events. Event Related Desynchronization (ERD) is a decrease in the power of the EEG in a given frequency band, all in relation to a particular event. The most well-known ERD is that caused by the opening of the eyes and which is visible in the frequency band of the alpha wave. These desynchronizations are indeed very widespread in the alpha band, especially during tasks involving memory or anything related to perception (He, 2013).

Conversely, Event Linked Synchronization (ELS) is an increase in the power of the EEG in a given frequency band. While the overall response of EEG signals to the same event is the same for each user, the precise characteristics may vary, such as the extent of desynchronizations and the frequencies where they are most visible or when they start. BCIs based on the ERD method therefore need a learning phase in order to memorize the user's brain response to the event studied. Then, the EEG signals are analyzed during the use of the $\mathrm{BCI}$ in order to find this response and thus determine a command to send.

The main advantage of the ERD and ELS method is that it uses internal events. Thus a BCI using this method does not require additional elements to generate the stimuli. However, the difficulty of increasing the number of detectable commands currently limits the resolution of the systems offered.

The EEG is a non-invasive measurement method that stands out in the field of BCI. Indeed, its reduced cost compared to other measurement means, as well as its small footprint, make it a method of choice for developing BCI at lower cost. The majority of the systems proposed are based on the analysis of evoked potentials, which correspond to modifications of the cerebral rhythms following exposure to external or internal events. However, these systems suffer from the lack of spatial resolution of the measurement by EEG, which implies either a reduced number of commands carried out by $\mathrm{BCI}$, or an extended command detection time, which removes the possibility of applications in real time and therefore limits the current perspectives of the field of BCI.

The spatial resolution of EEG can be improved by solving the EEG inverse problem, which allows to determine the distribution of electrical sources in the brain from EEG. Currently, the main difficulty is the time needed (several hours) to compute the matrix which is used to solve the EEG inverse problem. The solution to provide a hardware acceleration of the matrix computation can be done by dedicated electronic architecture. First results show that the proposed architecture divides the calculation time by a factor of 60 on a programmable circuit. This acceleration opens up new perspectives for EEG BCI. 


\section{The inverse EEG problem - a new trend towards solving non-invasive high-resolution $B C I$}

The electrical activity of the brain is a spatio-temporal process, which is indeed distributed in the 3 dimensions of the brain and evolves over time. The resolution of the 2 domains is therefore essential to analyze the precision of the cerebral imaging method used. If the strong point of the EEG is its temporal resolution, of the order of a millisecond, the spatial resolution is meanwhile much more limited for two reasons. The first of these reasons is the limitation of spatial sampling. In fact, the classic international system 10-20 places electrodes on a helmet with an average gap of 6 $\mathrm{cm}$ between 2 of them (Nunez, Silberstein, Cadusch, Wijesinghe, \& Westdorp, Srinivasan, 1994). Recent developments in EEG systems have made it possible to offer better resolution systems with 64 to 256 electrodes. For example, with 124 electrodes, the distance between the 2 measurement points is reduced to $2.5 \mathrm{~cm}$ (Gevins, A., Le, J., Martin, N. K., Brickett, P., Desmond, J., \& Reutter B., 1994). The second reason for the lack of spatial resolution comes from the different conduction effects. To reach the electrodes of the EEG helmet, the electrical potentials generated by the neurons must cross, among other things, the nervous tissue, the cerebrospinal fluid, the skull and the scalp. This path implies that the signal arriving at the electrodes is attenuated, distorted and noisy (Nunez, Srinivasan, 2009). We must therefore seek to correct these faults with dedicated techniques in order to improve the spatial resolution of the EEG. This is where distinct but closely related problems come into play - the direct problem and the inverse problem of the EEG. In fact, their resolutions are required in order to establish a high resolution map of the brain's electrical activity from an EEG measurement.

From the knowledge of the distribution of electrical sources in the brain and models of the conduction properties of the head, the direct problem of the EEG aims to determine the electric field generated by these sources. The solution can take the form of electrical potentials, such as the potentials on the surface of the cerebral cortex or the scalp. This solution can also be represented by other metrics such as for example a current density distribution. The direct problem is well defined and has a unique solution, defined by Maxwell's equations (Malmivuo, Plonsey, 1995). Solving this direct EEG problem helps to establish the relationship between electrical sources in the brain and what is actually measured by the electrodes. This relationship can then be represented in the form of a transfer matrix whose coefficients are dependent on the geometry and the conduction characteristics of the head of the subject studied.

On the other hand, the inverse problem of the EEG is interested in determining the location and importance of the active electrical sources in the brain from the potentials measured by the EEG headset and the conduction characteristics of the head of subject. This duality between direct problem and inverse problem is illustrated in Figure 3. Unlike the direct problem, the inverse problem does not admit of a single solution. Indeed, Helmholtz proved in 1853 that an infinity of configurations of sources in a volume can generate a given set of potentials measured at its surface (Hermann von Helmholtz, Wikipedia, 2020). Other constraints must therefore be added in order to obtain a single solution.

These constraints can be anatomical, physiological, spatio-temporal or even functional and come from community knowledge about how the brain works. When solving the inverse problem of EEG, several source models can be considered. The isolated 
sources model is concerned with determining the electrical activity of the brain at the neuron scale, while the distributed sources model considers groupings of sources located in the 3 dimensions of the brain. The choice of source model depends on the intended application, although the primary objective of solving the opposite EEG problem remains the same - finding a representation of electrical sources in the brain that explains the potentials measured by the EEG helmet. Neuroimaging based on the inverse problem therefore makes it possible to establish a high-resolution mapping of the brain in a non-invasive and inexpensive manner.

Neuroimaging by solving the inverse EEG problem is an interesting way to offer non-invasive high resolution BCI in the long term. This method is already used in scientific disciplines which do not have significant time constraints. Therefore, in the case of an epilepsy study, the calculations are made after the measurement session. In order to apply new trends in the field of BCIs, it is therefore necessary to choose a method in which data processing can be carried out simultaneously with the measurement of EEG signals.

\section{Interface brain machine by other non-invasive methods}

\section{Functional Near-Infrared Spectroscopy (fNIRS)}

Functional Near-Infrared Spectroscopy or Optical Topography, as it is called in Japan exclusively, is the use of near-infrared spectroscopy (NIRS) for functional neuroimaging. Using fNIRS, cerebral hemodynamic responses are measured by near-infrared light, which go in line with cerebral activation or deactivation. In particular, this technology is capable of visualizing changes both in oxy- and deoxyhaemoglobin concentration. fNIRS is based on the absorption of near infrared light by haemoglobin. The light moves, or propagates, through the head and lends information about blood volume, flow and oxygenation. This technique is safe, non-invasive, and can be used with other imaging modalities.

fNIRS is a non-invasive imaging method involving the quantification of chromophore concentration resolved from the measurement of near infrared (NIR) light attenuation or temporal or phasic changes. fNIRS spectrum light takes advantage of the optical window in which:

- skin, tissue, and bone are mostly transparent to NIR light (700-900 nm spectral interval),

- haemoglobin and deoxygenated-haemoglobin are strong absorbers of light. These are the principals adapted from pulse oximeters.

There are six different ways for infrared light to interact with the brain tissue: direct transmission, diffuse transmission, specular reflection, diffuse reflection, scattering, and absorption. fNIRS focuses on absorption: differences in the absorption spectra of deoxy-haemoglobin and oxy-haemoglobin allow the measurement of relative changes in haemoglobin concentration through the use of light attenuation at multiple wavelengths. Two or more wavelengths are selected, with one wave length above and one below the isosbestic point of $810 \mathrm{~nm}$, at which deoxy-haemoglobin and oxy-haemoglobin have identical absorption coefficients. Typically, the light emitter and detector are placed ipsilaterally (each emitter/detector pair on the same side) on the subject's skull so recorded measurements are due to back-scattered (reflected) light following 
elliptical pathways. fNIRS is the method the most sensitive to scalp and skull, so in order to have an increased sensitivity to the superficial cortex, there needs to be a larger source-detector ratio (Functional near-infrared spectroscopy, Wikipedia, 2020).

fNIRS technology is dependent on the level of oxygen in the blood. Due to light limits, fNIRS cannot be used for cortical measurements activities in the brain below $4 \mathrm{~cm}$. Also, the time resolution of fNIRS is relatively lower than electrical or magnetic signals.

\section{Functional Magnetic Resonance Imaging (fMRI)}

Functional Magnetic Resonance Imaging (fMRI) measures brain activity by detecting changes associated with blood flow. This technique relies on the fact that cerebral blood flow and neuronal activation are coupled. When an area of the brain is in use, blood flow to that region also increases. The primary form of fMRI uses the blood-oxygen-level dependent contrast. This is a type of specialized brain scan used to map neural activity in the brain or spinal cord of humans by imaging the change in blood flow (hemodynamic response) related to energy use by brain cells. fMRI has come to dominate brain mapping research, because it does not require people to undergo injections or surgery, to ingest substances, or to be exposed to ionizing radiation. This measure is frequently corrupted by noise from various sources, hence, statistical procedures are used to extract the underlying signal. The resulting brain activation can be graphically represented by color-coding the strength of activation across the brain or the specific region studied (Functional magnetic resonance imaging, Wikipedia, 2020).

fMRI has higher spatial resolution and collects information from the brain from deeper areas than fNIRS. However, the same disadvantage of fMRI as of fNIRS is the low time resolution slowed down due to blood flow. The most significant disadvantage of fMRI is the need for an expensive and heavy magnetic field scanner. Required scanners are non-relocatable or require a lot of effort to relocate.

The fMRI method as well as the fNIRS method show the required high spatial resolution. The main disadvantage is the time delay caused by the fact that the flow of oxygenated blood connects to the nerve cells after a few seconds. Another disadvantage is that $\mathrm{fMRI}$ is laboratory bound and fNIRS only reaches approximately $3 \mathrm{~cm}$ deep into the brain (Kübler, 2019).

\section{Positron emission tomography (PET)}

Positron emission tomography (PET) is an imaging technique that uses radioactive substances to visualize and measure metabolic processes in the brain and the human body. PET is mainly used in the area of medical imaging for detecting or measuring changes in physiological activities like metabolism, blood flow, regional chemical composition, and absorption, and therefore, it is also called a functional imaging technique. The PET method uses radioactive materials for imaging. A tracer is injected into the body, which gets trapped within the tissues of interest. The unstable nucleus of radio-ligand emit positrons, which combine with neighbouring electrons to produce gamma rays in the opposite direction at 180 degrees to each other. These gamma rays are detected by the ring of detector placed within the donut-shaped body of the scanner. The energy and location of these gamma rays are recorded and used 
by a computer program to reconstruct three-dimensional (3D) images of tracer concentration within the body.

In modern PET computed tomography scanners, PET images are often reconstructed with the aid of a computed tomography X-ray scan performed on the patient during the same session, in the same machine. PET imaging is best performed using a dedicated PET scanner. It is also possible to acquire PET images using a conventional dual-head gamma camera fitted with a coincidence detector. The quality of gamma-camera PET imaging is lower, and the scans take longer to acquire. However, this method allows a low-cost on-site solution to institutions with low PET scanning demand.

Alternative methods of medical imaging include single-photon emission computed tomography (SPECT). SPECT is an imaging technique similar to PET that uses radio ligands to detect molecules in the body. SPECT is less expensive but provides inferior image quality than PET.

\section{Magnetoencephalography (MEG)}

Magnetoencephalography (MEG) is a functional neuroimaging technique for mapping brain activity by recording magnetic fields produced by electrical currents occurring naturally in the brain, using very sensitive magnetometers. Arrays of SQUIDs (superconducting quantum unit interference devices) are currently the most common magnetometer, while the SERF (spin exchange relaxation-free) magnetometer is being investigated for future machines. Applications of MEG include basic research into perceptual and cognitive brain processes, localizing regions affected by pathology before surgical removal, determining the function of various parts of the brain, and neurofeedback. This can be applied in a clinical setting to find locations of abnormalities as well as in an experimental setting to simply measure brain activity.

In research, MEG's primary use is the measurement of time courses of activity. MEG can resolve events with a precision of 10 milliseconds or faster, while functional MRI (fMRI), which depends on changes in blood flow, can at best resolve events with a precision of several hundred of milliseconds. MEG also accurately pinpoints sources in primary auditory, somatosensory, and motor areas. For creating functional maps of human cortex during more complex cognitive tasks, MEG is most often combined with fMRI, as the methods complement each other. Neuronal (MEG) and hemodynamic (fMRI) data do not necessarily agree, in spite of the tight relationship between local field potentials and blood oxygenation level-dependent (BOLD) signals. MEG and BOLD signals may originate from the same source (though the BOLD signals are filtered through the hemodynamic response).

MEG is also being used to better localize responses in the brain. The openness of the MEG setup allows external auditory and visual stimuli to be easily introduced. Some movement by the subject is also possible as long as it does not jar the subject's head. The responses in the brain before, during, and after the introduction of such stimuli/movement can then be mapped with greater spatial resolution than was previously possible with EEG. Psychologists are also taking advantage of MEG neuroimaging to better understand relationships between brain function and behaviour. For example, a number of studies have been done comparing the MEG responses of patients with psychological troubles to control patients. There has been great success 
isolating unique responses in patients with schizophrenia, such as auditory gating deficits to human voices (Cui, Cunnington, Beisteiner, Deecke, 2012). MEG is also being used to correlate standard psychological responses, such as the emotional dependence of language comprehension (Magnetoencephalography, Wikipedia, 2020).

\section{Electrooculography (EOG)}

In 1989 report was given on control of a mobile robot by eye movement using Electrooculography (EOG) signals. A mobile robot was driven from a start to a goal point using five EOG commands, interpreted as forward, backward, left, right, and stop. The EOG as a challenge of controlling external objects was presented by Vidal (1973).

\section{Forecast}

A new study from Juniper Research ${ }^{1}$ predict good news for Brain-Computer Interfaces (BCI) and has found that global hardware sales revenue from BCI will reach $\$ 19$ billion per annum by 2027 , up from an estimated $\$ 2.4$ billion in 2018 . BCIs bridge the gap between technology and the brain, interpreting brain signals for the purpose of interpretation or control. Research is continuing to improve the quality of BCIs so that they can be ready to use for the general public in a few years.

The research found that the greatest impact of BCIs will be when used for concentration monitoring, where EEG (Electroencephalogram) technology can be leveraged to monitor fatigue. This is crucial for industrial businesses, which strive to improve safety and productivity. Juniper predicted that heavy industry will use EEG to replace more expensive existing monitoring systems. Research author Nick Maynard explained: "EEG is more accurate than current wrist-based optical sensors for concentration monitoring, so adoption where concentration is crucial in high-risk environments is anticipated to be a big driver in the market."

The research found that while shipments of BCI devices for consumer uses such as guided meditation account for a very low proportion of device shipments presently, of under $1 \%$ in 2018 , the proportion will climb to over $6 \%$ of a much larger market in 2027. Juniper predicted that technology advancement in tandem with consumer virtual/mixed-reality uptake would facilitate new interface paradigms when integrated. This higher proportion will be aided by the lower average sales price of these devices, just $\$ 270$ in 2027 , compared to $\$ 11,570$ in the medical area.

\section{CONCLUSION}

A Brain-Computer Interface (BCI) is a connection system between the brain and a computer. It therefore offers the user the possibility of performing tasks without the intermediary of the peripheral nerves. Therefore, it is mainly intended for medicine for the treatment of people with disabilities. There are many examples - a subject with a prosthesis can control the movements of the latter with his thought, like a person who has never lost his limbs. Likewise, BCI makes it possible to speak and write through computers using neurons.

Juniper Research is an analyst house that focuses on digital technology markets, providing reports, consulting, technology, trends and forecasting. Available: https://www.juniperresearch.com. 
It's not just the suffering who can benefit from BCI. Indeed, they are also useful for the general public. Gamers can for example get a unique gaming experience using these systems. What could be better than having a brain controller? In short, BCIs seem to embody the future of virtual reality and mixed reality. You just have to wait until the project is completed and it is fully functional.

The BCI is somewhat of a miracle product of computing and science. However, it also requires effort on the part of the person who uses it and who wishes to use it more easily. Indeed, it takes adaptation time and exercises to refine the control of the system which operates in a closed loop. This means that when you first use it, the subject will not immediately master everything. He/she will have to observe the results of his brain commands and apprehend the beast until the manipulation becomes automatic. A bit like a baby who discovers the world, the person will gradually tame his/her different capacities.

However, studies have shown that $30 \%$ of the world's population is currently unable to control BCIs. This is pushing researchers to work on improving the system so that the devices can finally hit the market. BCI can open many doors. You just have to wait until everything is developed to take advantage of it. By waiting, we can already save because the price of a consumer device would be estimated at around 300 euros (Megabyte, 2020).

\section{REFERENCES}

Abdellah, M. (2017). Face au développement des neurotechnologies, des chercheurs défendent la reconnaissance de nouveaux droits fondamentaux. France 24 [online]. Available: https://www.france24.com/fr/20170427-face-developpement-neurotechnologies -chercheurs-defendent-reconnaissance-nouveaux-droits-fondamentau.

Bardon, L. (2017). Les neurotechnologies imposent de revisiter les lois liées au droit de l'homme [online]. Available: http://paris-singularity.fr/in-a-neurotechnology-future-human -rights-laws-will-need-to-be-revisited/.

Bezard, E. (2018). L’interface cerveau-machine: « un dialogue » pour réparer le corps, The Conversation [online]. Available: https://theconversation.com/linterface-cerveau -machine-un-dialogue-pour-reparer-le-corps-101558.

Charte des droits fondamentaux de l'UE, Journal officiel de l'Union européenne C 303/17 14.12.2007 [online]. Available: https://fra.europa.eu/fr/eu-charter/article/3-droit -lintegrite-de-la-personne.

Cheminat, J. (2017). Face au « hacking du cerveau », de nouveaux droits de l'homme?, Silicon.fr [online]. Available: https://www.silicon.fr/face-au-hacking-du-cerveau-de -nouveaux-droits-de-lhomme-173491.html.

Clerc, M., Bougrain, L., \& Lotte, F. (2016). Brain-computer interfaces 1: Methods and perspectives (Cognitive Science). London: Wiley-ISTE.

Clerc, M., Bougrain, L., \& Lotte, F. (2016). Brain-computer interfaces 2: Technology and applications (Cognitive Science). London: Wiley-ISTE.

Cui, R., Cunnington, R., Beisteiner, R., Deecke, L. (2012). Effects of force-load on cortical activity preceding voluntary finger movement: Whole-scalp magnetoencephalography of the Bereitschaftsfeld. Neurology, Psychiatry and Brain Research, June 2012, 18(3), 97-104. Available: https://doi.org/10.1016/j.npbr.2012.03.001.

Dartigues, L. (2018). Une irrésistible ascension? Le neurodroit face à ses critiques. Zilsel 2018/1, no. 3, pp. 63-103. Available on: https://www.cairn.info/revue-zilsel-2018-1 -page-63.htm?try_download=1. 
Farnsworth, B. (2017). EEG Headset Prices - An Overview of 15+ EEG Devices. July 2017 [online]. Available: https://imotions.com/blog/eeg-headset-prices/.

Friedman, D. et al. (2010). Human-Computer Interface Issues in Controlling Virtual Reality with Brain-Computer Interface. In: Human-Computer Interaction, 2010, 25, 67-93. Available: https://www.idc.ac.il/he/research/arl/Documents/publications/HumanComputerInterfaceIssues.pdf.

Functional magnetic resonance imaging (2020). Wikipedia [online]. Available: https:// en.wikipedia.org/wiki/Functional_magnetic_resonance_imaging.

Functional near-infrared spectroscopy (2020). Wikipedia [online]. Available: https:// en.wikipedia.org/wiki/Functional_near-infrared_spectroscopy.

Gevins, A., Le, J., Martin, N. K., Brickett, P., Desmond, J., \& Reutter, B. (1994). High resolution EEG: 124-channel recording, spatial deblurring and MRI integration methods. Electroencephalography and Clinical Neurophysiology, May 1994, 90(5), 337-358. Available: http://linkinghub.elsevier.com/retrieve/pii/0013469494900507.

Guzman, C.-E. (2017). Face aux neurotechnologies, de nouveaux droits de l'homme s'avèrent nécessaires, Neurosciences Appliquées [online]. Available: https://up-magazine.info/le-vivant /neurosciences / 6642-face-aux-neurotechnologies-de-nouveaux-droits-de-l-homme -s-averent-necessaires/.

Haladová, E., Nechvátalová, L. (2010). Vyšstřovací metody hybného systému. Brno: Národní centrum ošetřovatelství a nelékařských zdravotnických oborů.

He, B. (2013). Neural Engineering. Publisher: McGraw-Hill Education, e-book.

Hemoglobin (2020). Wikipedia [online]. Available: https://en.wikipedia.org/wiki /Hemoglobin.

Hermann von Helmholtz (2020). Wikipedia [online]. Available: https://en.wikipedia.org /wiki/Hermann_von_Helmholtz.

Interface cerveau-machine (2020). INSERM [online]. Available: https://www.inserm.fr /information-en-sante/dossiers-information/interface-cerveau-machine-icm.

Jonathan (2017). L'Imagerie par Résonnance Magnétique (IRM). Entraide-ESI-IDE [online]. Available: http://entraide-esi-ide.com/limagerie-par-resonnance-magnetique-irm/.

Krajča, V., Mohylová, J. Číslicové zpracování neurofyziologických signáli̊. Praha: Česká technika - nakladatelství ČVUT, 2011.

Kübler, A. (2019). The history of BCI: From a vision for the future to real support for personhood in people with locked-in syndrome. Neuroethics [online]. 1-18 [cit. 2019-10-22].

Libessart, E. (2018). Interface cerveau-machine: de nouvelles perspectives grâce à l'accélérationmatérielle. Electronique. Ecole nationale supérieure Mines-Télécom Atlantique [online]. Available: https://tel.archives-ouvertes.fr/tel-02017104/document.

Magnetoencephalography (2020). Wikipedia [online]. Available: https://en.wikipedia.org /wiki/Magnetoencephalography.

Malmivuo, J., Plonsey, R. (1995). Bioelectromagnetism: Principles and Applications of Bioelectric and Biomagnetic Fields. 1st edition (July 27, 1995). Oxford: Oxford University Press.

Marion, F. (2017). Les « sciences computationnelles », nouvelle frontière pour la connaissance?. Up-Magazine [online]. Available: http://up-magazine.info/index.php /technologies-a-la-pointe/technologies/7131-les-sciences-computationnelles-nouvelle -frontiere-pour-la-connaissance.

Megabyte: Interfaces cerveau-machine (BMI): une croissance fulgurante du marché est attendee (2020). Megabyte [online]. Available: https://www.megabyte.be/interfaces -cerveau-machine-bmi-une-croissance-fulgurante-du-marche-est-attendue/.

Montalto, C. (2013). What are inverse problems? [online]. Available: https://cmontalto .wordpress.com/2013/03/08/what-are-inverse-problems/.

Nunez, P. L., Silberstein, R. B., Cadusch, P. J., Wijesinghe, R. S., \& Westdorp, A. F., Srinivasan, R. (1994). A theoretical and experimental study of high resolution EEG based on surface 
Laplacians and cortical imaging. Electroencephalography and Clinical Neurophysiology, Jan. [online], 90(1), 40-57. Available: http://www.sciencedirect.com/science/article /pii/0013469494901120

Nunez, P. L., Srinivasan, R. (2009). Electric Fields of the Brain: The neurophysics of EEG [online]. May 2009. Published to Oxford Scholarship.

Oullier, P. (2012). Le cerveau etla loi: Analyse de l'émergence du neurodroit [online]. Available: http://archives.strategie.gouv.fr/cas/system/files/cas-dqs_dt-neurodroit _11septembrereduit_0.pdf.

Pánek, D. (2016). Elektroencefalografické koreláty pohybového chování a výkonnostní zátěže. Praha: Nakl. Karolinum.

Richmond, S., Rees, G., \& Edwards, S. (2012). I Know What You're Thinking: Brain imaging and mental privacy. Oxford: Oxford University Press.

Sarracanie, M., LaPierre, C. D., Salameh, N., Waddington, D. E. J., Witzel, T., \& Rosen, M. S. (2015). "Low-Cost High-Performance MRI”. Scientific Reports, Oct. [online], 5, p. 15177. Available: https://www.nature.com/articles/srep15177.

Schomer, D. L., \& Lopes Da Silva F. (2012). Niedermeyer's Electroencephalography: Basic Principles, Clinical Applications, and Related Fields. Publisher: Lippincott Williams \& Wilkins.

Šesták, J. (2017). Psychologická kontinuita jako klič k identitě Já. Bakalářská práce [online]. Plzeň: Západočeská univerzita v Plzni, Fakulta filozofická. Available: https://dspace5.zcu .cz/bitstream/11025/26770/1/Jakub\%20Sestak\%20BC\%20final.pdf.

Šilhavý, R., Šilhavý, P., Prokopová, Z. (2017). Cybernetics Approaches in Intelligent Systems. Editor: Springer.

Šíma, J. (2019). The Use of Digital Media during the 2018 FIFA World Cup. Proceedings of the International Conference Marketing Identity 2018, pp. 277-288.

Vidal, J. J. (1973). Toward direct brain-computer communication. Annual Review of Biophysics and Bioengineering, 2(1), 157-180. Available: https://www.annualreviews.org/doi /abs/10.1146/annurev.bb.02.060173.001105.

Žák, R. (2012). Zpracování mozkové aktivity v Bci systémech. Trilobit 1/2012. Editor: Univerzita Tomáše Bati ve Zlíně.

Žák, R. (2013). Řizení systémů pomocí aktivizace mozkových center. Zlín: Univerzita Tomáše Bati ve Zlínè. 